\title{
Erratum to: Stigma and the Renaming of Schizophrenia
}

\author{
Toshimasa Maruta and Chihiro Matsumoto
}

\section{Erratum to:}

Chapter 32 in: W. Gaebel et al. (eds.), The Stigma of Mental Illness - End of the Story?, DOI 10.1007/978-3-319-27839-1_32

Erratum text:

There are two corrections on p. 574:

(1) the last line in Table 32.1 the abbreviation of Psychosis susceptibility syndrome (PPS) should be PSS instead of PPS

(2) in line 13 of the next paragraph it should be Klijn instead of Klijin

The updated online version for this chapter can be found at DOI 10.1007/978-3-319-27839-1_32 